\title{
EFFECT OF AQUEOUS EXTRACTS OF THREE DIFFERENT PLANTS ON MYZUS PERSICAE SULZER (HEMIPTERA: APHIDIDAE) INFESTING PEPPER PLANTS UNDER LABORATORY CONDITIONS
}

\author{
LASSAAD MDELLEL ${ }^{1, *}$, AHMED ABDELLI 2 , KHALED OMAR ${ }^{2}$, \\ WALEED EL-BASSAM ${ }^{2}$, and MAZEN AL-KHATEEB ${ }^{1}$
}

1 Organic Farming Development Project, the Palladium Group, Riyadh, Saudi Arabia.

2 Plant Protection Department, National Organic Agriculture Centre, Kingdom of Saudi Arabia.

*Corresponding author: lassaad.mdallel@thepalladiumgroup.com

\begin{abstract}
This study aimed to determine the percentage infestation and population parameters of the green peach aphid Myzus persicae under laboratory conditions and evaluate the effect of aqueous extracts of three different plants (pot marigold: Calendula officinalis, mint: Mentha viridis and rosemary: Salvia rosmarinus) on the mortality of this aphid. Extracts of these plants were used at three concentrations $(C 1=15 \%, C 2=30 \%$ and C2 $=45 \%)$. Results indicate a percentage infestation of $76.9 \pm 9.4 \%$, a mean relative growth rate of $0.062 \pm 0.007$ and generation time of $11.12 \pm 1.42$ days. All treatments reduced the numbers of aphids and statistically significantly reduced the number $(a<0.01)$ recorded after treatment with $\mathrm{C} 1, \mathrm{C} 2$ and $\mathrm{C} 3$ of each extract. $C$. officinalis extract was more effective than those of $M$. viridis and S. rosmarinus. The highest mortality $(69.82 \pm 5.23 \%)$ and efficacy $(61.71 \pm 4.46 \%)$ were recorded for the $C 3$ of aqueous extract of $C$. officinalis, whereas the lowest mortality $(38.24 \pm 2.42 \%)$ and efficacy $(32.41 \pm 1.23 \%)$ were recorded for the $C 1$ of extract of $M$. viridis. The data provided indicate that aqueous extracts of $C$. officinalis, $M$. viridis and S. rosmarinus have an insecticidal effect on $M$. persicae and can be integrated into a pest management strategy to reduce $M$. persicae abundance on pepper plants.
\end{abstract}

Keywords: botanical extracts; efficacy; mortality; Myzus persicae; population parameters

\section{Introduction}

Pepper (Capsicum spp.) is an annual herbaceous plant belonging to the Solanaceae family, which includes commercial vegetables such as tomato, eggplant, tobacco and potato (Tripodi and Komar 2019). It is one of the most popular vegetable crops throughout the world and a source of vitamins $\mathrm{C}$ and $\mathrm{E}$, provitamin $\mathrm{A}$, carotenoids and phenolic compounds that offer health benefits for consumers (Agwu et al. 2018). Despite the importance and popularity of pepper, several pests, such as insects, fungi, bacteria, viruses and nematodes adversely affect its production worldwide.

Among the insects, the green peach aphid, Myzus persicae Sulzer (Hemiptera, Aphididae) is one of its most serious pests (Blackman and Eastop 2006; van Emden and Harrington 2007; Mdellel et al. 2019). It can occur on the underside of the leaves and on young plants at high densities, which causes deformation of leaves, reduces plant growth and infects the plants with virus, which reduce yield and the quality in terms of its nutritional content (Blackman and Eastop 2006; Bass et al. 2014). The green peach aphid is controlled mainly by using chemical insecticides.

However, the use of chemical insecticides has serious disadvantages, such as human and animal poisoning, water contamination, development of pest resistance, death of pollinating agents and natural enemies (Ofuya and Okuku 1994; Bass et al. 2014). Therefore, there is a need to investigate alternative means of control that can reduce chemical pesticide-related problems (Nahusenay and Abate 2018). Among these, botanical insecticides are an important group of naturally occurring pesticides, which are usually safer for humans, animals, environment and natural enemies than chemical insecticides (Devi et al. 2016).

Currently, the use of plant extracts and essential oils to control insect pests is widely used. Indeed, some plants are chemically protected against insects or contain various biologically active compounds that can be toxic to insect pests, anti-feedants, inhibit growth, inhibit oviposition and even sterilize insects (Sayed et al. 2020). In addition, plant extracts are less toxic to humans, easily degrade in the environment and less persistent than chemical pesticides (Mwine et al. 2011; Silva et al. 2016).

Among the biological active compounds, pyrethrin, which is extracted from Chrysanthemum spp. kills insects at low concentrations and has many others advantages such as rapid degradation and is less toxic to beneficial insects (Shawket el al. 2011). Many other plants like neem (Azadirachta indica), tinjut (Otostegia integrifolia), crinum (Crinum ornatum) and common sage (Salvia officinalis) have been used to control insects (Nahusenay and Abate 2018; Sayed et al. 2020). Unfortunately, insecticidal effects of aqueous extracts of many others plants, such as pot marigold (Calendula officinalis), mint (Mentha viridis) and rosemary (Salvia rosmarinus) on aphids and the most effective concentrations are unknown.

In this study, the biological parameters of M. persicae under laboratory conditions and pesticidal effects of 
aqueous extracts of C. officinalis, $M$. viridis and S. rosmarinus applied as a foliar spray at three different concentrations were investigated.

\section{Materials and Methods}

\section{Insects and plants}

M. persicae collected from pepper plants cultivated in greenhouses at the National Organic Agriculture Centre, Unaiza, Kingdom Saudi Arabia, in January 2020. This aphid was reared on pepper plants in Plexiglas cages $(50 \times 50 \times 50 \mathrm{~cm})$ at $25 \pm 2{ }^{\circ} \mathrm{C}$, relative humidity of $60 \pm 10 \%$ and a photoperiod of $14 \mathrm{~L}: 10 \mathrm{D} \mathrm{h}$ for several generations (60 days) before use in the experiments. The cultivar of pepper used was Shakira. Pepper plants (Cultivar: Shakira) were reared in the laboratory at day/ night temperature ranging from 18 to $25^{\circ} \mathrm{C}, 60-80 \% \mathrm{RH}$, and under ambient light conditions. Plants at eight leaf stage of development, were transferred to $500 \mathrm{~mL}$ pots containing a substrate consisting of $1 / 3$ sand and $2 / 3$ peat in a greenhouse at $25 \pm 2{ }^{\circ} \mathrm{C}$, relative humidity of $60 \pm$ $10 \%$ and a photoperiod of $14 \mathrm{~L}: 10 \mathrm{D} \mathrm{h}$ and were watered on alternate days and no pesticides were used during the experiments.

\section{Infestation rate and population parameters of M. persicae on pepper}

At the twelve-leaf stage, wingless adult aphids were collected from the colony and transferred to pepper plants in a greenhouse. Fifteen plants were each infested with four adult aphids. The experiment was replicated 3 times and total number of plants used was 45 plants. Data collection started after 2 days after infestation and total number of leaves, infested leaves, and aphid number $/ \mathrm{cm}^{2}$ of leaf were counted every seven days over a period of two months. The mean relative growth rate (MRGR) and generation time (T) of $M$. percicae were determined according to Leather and Dixon (1984), and the F1 and F2 formulas of Ramade (2003):

$\operatorname{MRGR}=\left(\operatorname{lnN}\left(\mathrm{t}_{\mathrm{n}}\right)-\ln \mathrm{N}\left(\mathrm{t}_{\mathrm{n}-1}\right)\right) /\left(\mathrm{t}_{\mathrm{n}}-\mathrm{t}_{\mathrm{n}-1}\right)$

$\mathrm{T}=\log _{2} / \mathrm{MRGR}$

where $N\left(t_{n}\right)$ is aphid number/cm² of leaf at time $t_{n}$, $\mathrm{N}\left(\mathrm{t}_{\mathrm{n}-1}\right)$ is aphid number/ $\mathrm{cm}^{2}$ of leaf at time $\mathrm{t}_{\mathrm{n}-1}$.

\section{Plant samples and extracts}

Fresh leaves of marigold, Mint and rosemary were collected in March 2020 from plants growing in natural habitats at Al-Qassim as indicated in Table 1. Collected leaves were washed with water and dried, well ventilated in the shade for two weeks (Sarwar 2015). The dried leaves were cut and ground to a fine powder using an electrical grinder. Thirty percent stock solution was prepared for each plant separately. The mixtures were stirred thoroughly with a repeated agitation at $3 \mathrm{~h}$ intervals for
24 h. Three concentrations $(15,30$, and $45 \%)$ were prepared from the final extracts.

Table 1 Description of the three plants tested in the present study.

\begin{tabular}{|c|l|c|c|c|}
\hline No. & Common name & Scientific Name & Family name & Part used \\
\hline $\mathbf{1}$ & Marigold & Calendula officinalis & Asteraceae & Leaves \\
\hline $\mathbf{2}$ & Mint & Mentha viridis & Lamiaceae & Leaves \\
\hline $\mathbf{3}$ & Rosemary & Salvia rosmarinus & Lamiaceae & Leaves \\
\hline
\end{tabular}

\section{Bioassay}

To determine the insecticidal effect of aqueous extracts of selected plants, three leaves of each plants were marked and number of M. persicae on each marked leaf was counted 1 hour before bioassays. Using a hand-held sprayer, aphids on pepper plants were sprayed with different concentrations $(\mathrm{C} 1=15 \%, \mathrm{C} 2=30 \%$, and C3 $=45 \%)$ and the control (untreated) with water. Three infested plants were used for each concentration. Three, six, nine and 12 days after spraying the number of living aphids on each of the marked leaves was counted. Mortality of M. persicae population after 12 days were determined and the corrected efficacy percentage was calculated using Henderson and Tilton (1955) formula:

Corrected efficacy $(\%)=1-(\mathrm{n}$ in Co before treatment $\times \mathrm{n}$ in T after treatment $/ \mathrm{n}$ in Co after treatment $\times \mathrm{n}$ in $\mathrm{T}$ before treatment) $\times 100$. Where: $\mathrm{n}=$ number of M. percicae/selected leaf, $\mathrm{T}=$ Treated and $\mathrm{Co}=$ Control.

\section{Statistical analysis}

The data were subjected to one-way analysis of variance (ANOVA) using SPSS (2015) software program, version 23. Separation of means separation was done using DMRT (Duncan's multiple range tests) test $(\mathrm{P}<0.01)$.

\section{Results}

\section{Percentage infestation and population parameters of $M$. persicae on pepper}

The percentage infestation and mean relative growth rate of $M$. persicae on pepper plant cultivar Shakira under laboratory conditions are shown in Table 2. During this experiment, total number of leaves/pepper plant was $52.6 \pm 13.8$ and total number infested $39.8 \pm 7.24$. Per-

Table 2 Biological parameters of Myzus persicae on pepper plants in green house.

\begin{tabular}{|l|c|}
\hline Parameters & Average \pm SD \\
\hline Total leaves number & $52.6 \pm 13.8$ \\
\hline Infested leaves number & $39.8 \pm 7.24$ \\
\hline Infestation rate (\%) & $76.9 \pm 9.4 \%$ \\
\hline Aphid number/leaf cm ${ }^{2}$ & $11.24 \pm 2.3$ \\
\hline Mean relative Growth Rate (MRGR) & $0.062 \pm 0.007$ \\
\hline Generation time (T) & $11.12 \pm 1.42$ days \\
\hline
\end{tabular}


centage infestation was $76.9 \pm 9.4 \%$. The aphid population survey resulted in an average of $11.24 \pm 2.3$ aphids $/ \mathrm{cm}^{2}$ of leaf, mean relative growth rate of $0.062 \pm 0.007$ and generation time of $11.12 \pm 1.42$ days.

\section{Effect of aqueous extracts on Myzus persicae population}

Aphid numbers $/ \mathrm{cm}^{2}$ of leaf on treated and none treated pepper plants were recorded 3, 6, 9 and 12 days after

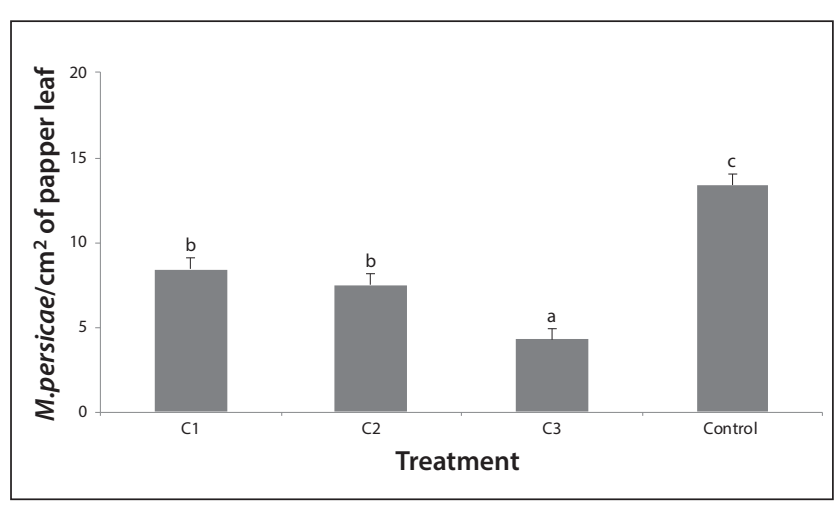

Fig. 1 Effect of an aqueous extract of marigold aqueous on the numbers of Myzus persicae $/ \mathrm{cm}^{2}$ of leaf of pepper plants. (Means followed by the same letter are not significantly different $(a<0.01$, Duncan's multiple range test).

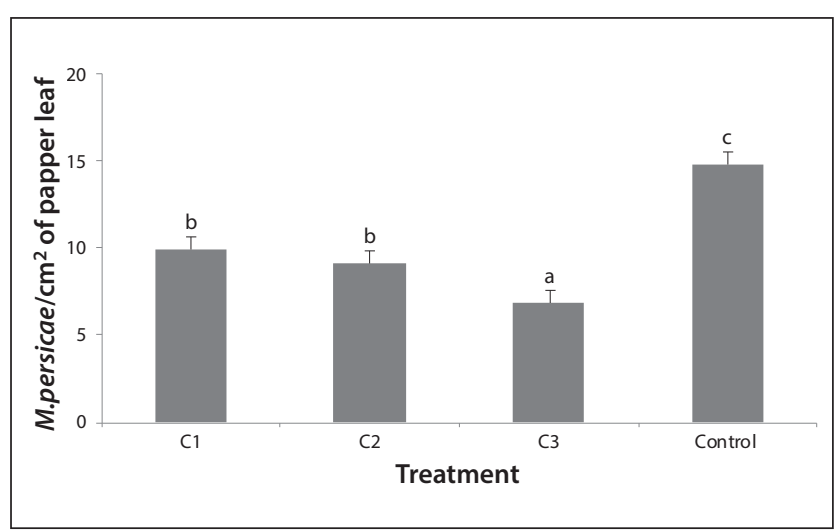

Fig. 2 Effect of an aqueous extract of mint on the numbers of Myzus persicae $/ \mathrm{cm}^{2}$ of leaf of pepper plants. (Means followed by the same letter are not significantly different $(a<0.01$, Duncan's multiple range test).

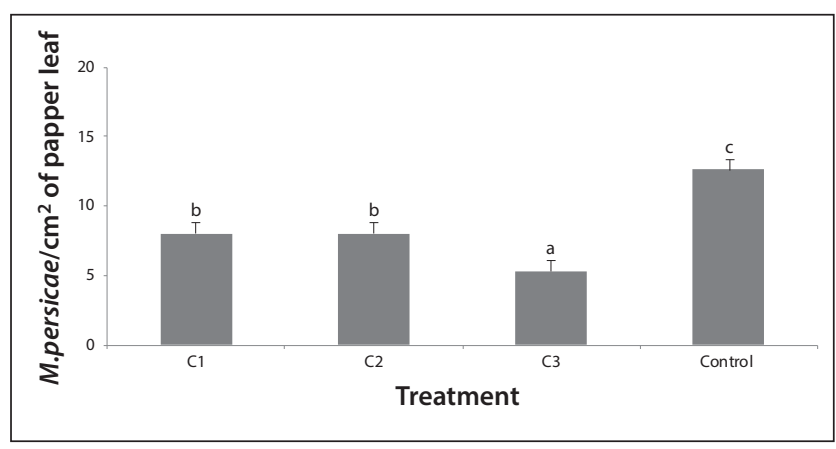

Fig. 3 Effect of an aqueous extract of rosemary on the numbers of Myzus persicae $/ \mathrm{cm}^{2}$ of leaf of pepper plants. (Means followed by the same letter are not significantly different $(a<0.01$, Duncan's multiple range test). spraying. Results indicate that all treatments decreased the numbers $/ \mathrm{cm}^{2}$ compared to untreated plants. Aphid numbers $/ \mathrm{cm}^{2}$ of leaf after treatment with $\mathrm{C} 1, \mathrm{C} 2$ and C3 of the $C$. officinalis extract were $8.37 \pm 1.33,7.43 \pm 1.46$ and $4.33 \pm 1.24$, respectively, and $13.37 \pm 2.81$ for untreated plants. That is, all concentrations in this treatment resulted in significant reductions $(F=48.57 ; a<0.01)$ in the numbers $/ \mathrm{cm}^{2}$ (Fig. 1). For M. viridis extract, the numbers were $9.95 \pm 1.12,9.11 \pm 1.86,6.83 \pm 1.66$ and $14.81 \pm 1.21$, respectively, and this treatment resulted in a significant reduction in the number of aphids $(\mathrm{F}=43$; $\alpha<0.01$ ) (Fig. 2). A reduced number $/ \mathrm{cm}^{2}$ was also recorded after treatment with the extracts of $S$. rosmarinus: $8.05 \pm 2.31,7.79 \pm 0.98$ and $5.27 \pm 1.32$, respectively, which are significantly different from the $12.61 \pm 1.93$ recorded on untreated plants (Fig. 3) $(\mathrm{F}=39.76 ; \alpha<0.01)$.

\section{Myzus persicae mortality and efficacy of plant extracts}

The efficacy of the different concentrations of aqueous extracts of $C$. officinalis, M. viridis and S. rosmarinus plants in killing $M$. persicae was determined. Results in Table 3 indicate that the treatments resulted in from 38.24 to $69.82 \%$ mortality. The percentage efficacy ranged between $32.41 \pm 1.23$ and $61.71 \pm 4.46$. The highest mortality $(69.82 \pm 5.23 \%)$ and efficacy $(61.71 \pm 4.46 \%)$ were recorded for treatment with $\mathrm{C} 3$ of the aqueous extract C. officinalis (Table 3). Whereas, the lowest mortality $(38.24 \pm 2.42 \%)$ and efficacy $(32.41 \pm 1.23 \%)$ were recorded for the treatment with $\mathrm{C} 1$ extract of $M$. viridis. Treatments with the three different concentrations of the extracts of $C$. officinalis, $M$. viridis and S. rosmarinus, resulted in a significant difference $(\alpha<0.01)$ in mortality and efficacy (Table 3 ). No significant differences $(\alpha>0.01)$ in mortality and efficacy were recorded for the treatments with $\mathrm{C} 1$ and $\mathrm{C} 2$ of $C$. officinalis, M. viridis and S. rosmarinus (Fig. 4, 5), but a significant higher $(\alpha<0.01)$ mortality and efficacy was recorded for the C3 extract of C. officinalis treatment compared to that of $M$. viridis and S. rosmarinus.

Table 3 Myzus persicae mortality and efficacy obtained across treatments with concentrations of extracts of selected plants.

\begin{tabular}{|l|c|c|c|}
\hline Selected plant & Concentration & Mortality (\%) & Efficacy (\%) \\
\hline \multirow{3}{*}{ C. officinalis } & C1 & $41.76 \pm 2.15 \mathrm{c}$ & $39.53 \pm 2.42 \mathrm{c}$ \\
\cline { 2 - 4 } & $\mathrm{C} 2$ & $48.20 \pm 3.45 \mathrm{~b}$ & $43.64 \pm 2.57 \mathrm{~b}$ \\
\cline { 2 - 4 } & $\mathrm{C} 3$ & $69.82 \pm 5.23 \mathrm{a}$ & $61.71 \pm 4.46 \mathrm{a}$ \\
\hline \multirow{3}{*}{ M. viridis } & $\mathrm{C} 1$ & $38.24 \pm 2.42 \mathrm{c}$ & $32.41 \pm 1.23 \mathrm{c}$ \\
\cline { 2 - 4 } & $\mathrm{C} 2$ & $43.34 \pm 3.74 \mathrm{~b}$ & $38.74 \pm 0.98 \mathrm{~b}$ \\
\cline { 2 - 4 } & $\mathrm{C} 3$ & $56.66 \pm 4.37 \mathrm{a}$ & $51.86 \pm 1.74 \mathrm{a}$ \\
\hline \multirow{3}{*}{ S. rosmarinus } & $\mathrm{C} 1$ & $42.71 \pm 3.35 \mathrm{c}$ & $37.23 \pm 0.79 \mathrm{c}$ \\
\cline { 2 - 4 } & $\mathrm{C} 2$ & $46.33 \pm 2.53 \mathrm{~b}$ & $40.85 \pm 1.37 \mathrm{~b}$ \\
\cline { 2 - 4 } & $\mathrm{C} 3$ & $61.76 \pm 4.46 \mathrm{a}$ & $56.81 \pm 1.67 \mathrm{a}$ \\
\hline
\end{tabular}

Means followed by the same letter are not significantly different ( $\alpha<0.01$, Duncan's multiple range test). C1, C2 and C3: Concentrations. 


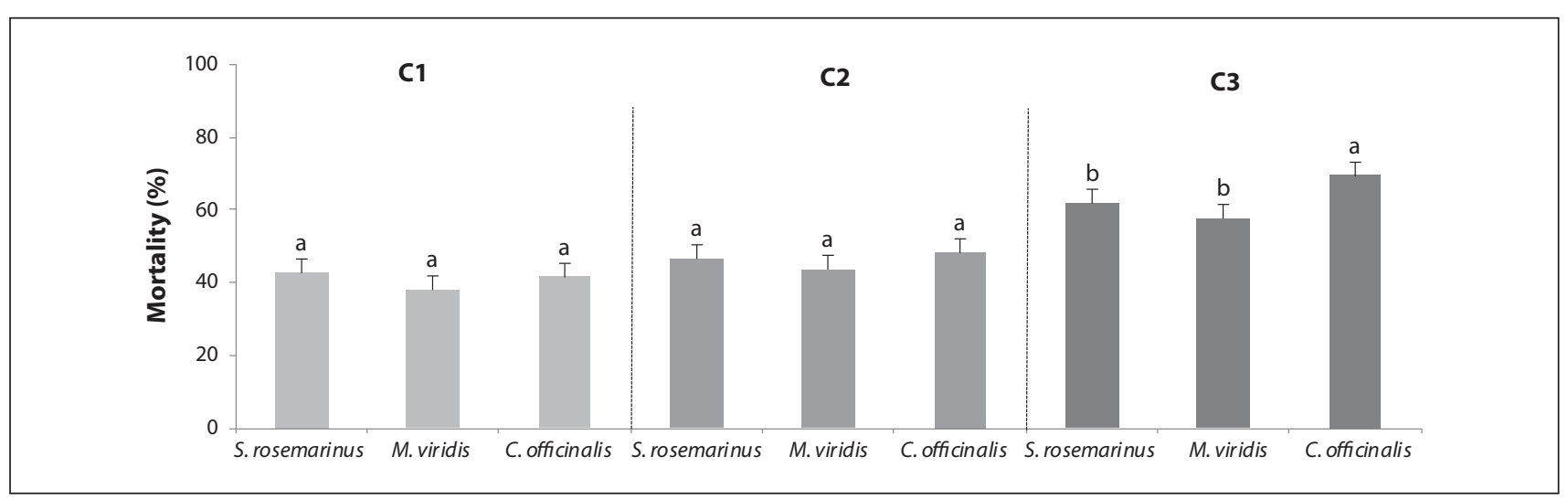

Fig. 4 Percentage mortality of Myzus persicae recorded treatments using three different concentrations of aqueous extracts of three species of plants. (Means followed by the same letter are not significantly different $(a<0.01$, Duncan's multiple range test).

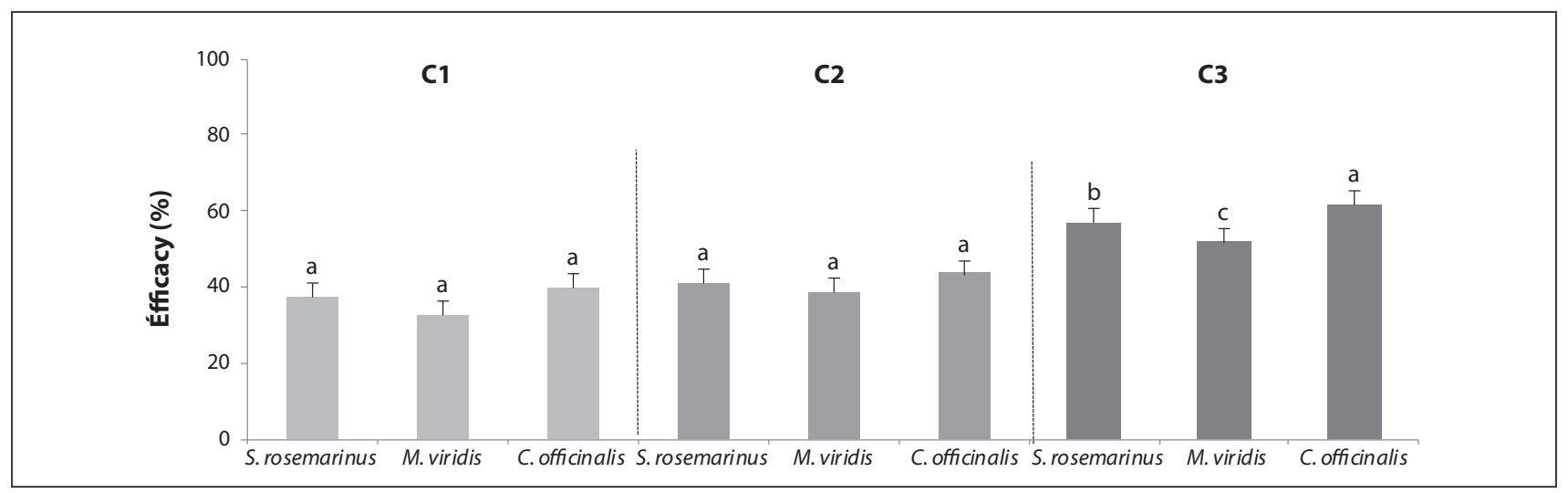

Fig. 5 Efficacy of three concentrations of aqueous extracts of three different species of plants in reducing the abundance Myzus persicae on pepper plants. (Means followed by the same letter are not significantly different $(a<0.01$, Duncan's multiple range test).

\section{Discussion and Conclusions}

Many species of plants contain bioactive compounds that are used as botanical insecticides for controlling pests. These botanical insecticides are naturally safe and harmless for consumers, but for insects are toxic, repellent, antifeedants or growth regulators (Sertkaya et al. 2010; Erdogan and Yildirim 2016). Of the insects, M. persicae, is classified as a serious pest of pepper plants worldwide due to its high potential growth rate.

In this study, percentage infestation and fitness of $M$. persicae were determined. Results indicate that $M$. persicae have a high reproductive potential on pepper, with a mean relative growth rate and a generation time of 0.062 and 11.12 days, respectively. Results also indicate a high percentage infestation $(76.9 \pm 9.6 \%)$. Fast development of $M$. persicae on pepper is reported with the generation time ranging between 10.23 and 13.51 days at temperatures between 20 and $25^{\circ} \mathrm{C}$ (Satar et al. 2008).

Similarly, Ali et al. (2021) report that M. persicae develops faster on pepper (9.96 days) than on cabbage (14.2 days) or crown daisy (10.9 days). In addition, Mdellel et al. (2019) reports that the MRGR of M. persicae on pepper at $25^{\circ} \mathrm{C}$ ranges between 0.046 and 0.068 depending on soil fertility. Several factors can influence the population growth of M. percicae, such the nitrogen level in the soil, which has a direct effect on host plant quality, which affect the growth rate of $M$. persiace (Mdellel and Ben Halima 2014). Similarly, Dixon (1987) shows that nitrogen is an important factor affecting the fitness of aphids.

The bioassays of the effectiveness of extracts of three species of plants (C. officinalis, M. viridis and S. rosmari$n u s$ ) in reducing the abundance of $M$. persicae on pepper plants revealed they were effective. Extracts at the highest concentration, $\mathrm{C} 3$, in all treatments was the most effective. Of the plant extracts, that of $C$. officinalis was more effective in reducing the abundance of $M$. persicae than that of $M$. viridis and S. rosmarinus. This might be attributed to differences in the insecticidal effects on aphids of the chemicals in these plants.

There is a report that flowers of C. officinalis contain flavonol glycosides, triterpene oligoglycosides, oleanane-type triterpene glycosides, saponins and a sesquiterpene glucoside (Ukiya et al. 2006). These compounds are highly toxic to plant sucking insects such as aphids and whiteflies and can inhibit feeding and growth of insect pests (Jankowska and Wilk 2011; Murrovhi et al. 2020). The other plant extracts (M. viridis and S. rosmarinus) were also effective in reducing the abundance of $M$. percicae. Samarasekera et al. (2008) report that the essential oil of Menthus spp. contains menthol which can adversely affect insects. Similarly, Ebadollah et al. (2020) 
report that essential oils isolated from Menthus plants can adversely affect insects and could act as a repellent and antifeedant. In addition, same authors indicate that essential oils of Menthus spp. and other Lamiaceae contain a monoterpenoid component, which damages pests.

Studies on Rosemarinus reveal that it contains volatile compounds, which can be extracted and used as an effective fumigant against various insects such as coleopteran (Tribolium spp.; Callosobruchus chinensis (L.).) and lepidopteran pests like Cadra cautella (Walker) (Lee et al. 2002; Isikber et al. 2006). Terpenes and monoterpenes of $R$. officinalis affect the central nervous system of insects by inhibiting acetylcholinesterase enzymes (Krzyzowski et al. 2020).

Our study indicates that extracts of three plants can markedly reduce the abundance of $M$. persicae on pepper plants, especially the highest concentration extract of C. officinalis, and consequently reduce the damage caused by this pest. Thus, plant extracts could potentially be used to control aphid pests on different crops and as an effective biological control agent for use in an integrated management strategy for controlling aphids.

Further studies on the chemical components of the extracts of the plants tested are needed in order to determine how they affect insects and their effect on the yield and quality of crops. In conclusion, the present study confirms that the potential growth of $M$. persicae on pepper plants is very high and likely to result in serious damage. Extracts of three different species of plants namely: C. officinalis, M. viridis and S. rosmarinus, at three different concentrations, increased the mortality of this aphid. All the plant extracts tested were effective in reducing aphid populations. The extract of $C$. officinalis was more effective than that of $M$. viridis and $S$. rosmarinus. The highest concentration of all extracts, especially that of C. officinalis, were effective in reducing aphid numbers and thus in decreasing the damage done by this pest. Therefore, it is recommended that these plant extracts are used to manage aphid abundance instead of chemical insecticides. The use of these plant extracts can reduce the cost and minimize the negative effects of chemical pesticides on consumers and the environment.

\section{Acknowledgements}

Organic Farming Development Project for funding this study. We acknowledge the National Organic Agriculture Centre administration for providing us with research facilities.

\section{REFERENCES}

Agwu JA, Odo GE, Ekeh F, Attamah GN, Uwagbae M, Eze C (2018) A survey of the insect pests and farmers practices in the cropping of yellow pepper Capsicum annum Linnaeus in Enugu State of Eastern Nigeria. Afr J Agri Res 13: 742-752.
Ali MY, Naseem T, Arshad M, Achraf I, Rizwan M, Tahir M, Rizwan M, Sayed S, Ullah MI, Khan RR, Amir MB, Pan M, Liu TX (2021) Host plant variations affect the biotic potential, survival and population projection of Myzus persicae (Hemitera: Aphididae). Insects 12: 375.

Bass C, Puinean AM, Zimmer CT, Denholm I, Field LM, Foster SP, Gutbrod O, Nauen R, Slater R, Williamson MS (2014) The evolution of insecticide resistance in the peach potato aphid, Myzus persicae. Insect Biochem Mol Biol 51: 41-54.

Blackman RL, Eastop VF (2006) Aphids on the world's herbaceous plants and shrubs. John Wiley and Sons, London, UK.

Devi E, Devi P, Deepshikha P (2016) Deepshikha. A review on prospects of Entomopathogenic fungi as potent biological control agents of insect pests. Int J Curr Res Biosci Plant Biol 3: 74-82.

Dixon AFG (1987) Parthenogenetic reproduction and the rate of increase in aphid. In: Minks AK, Harrewijn P (eds) Aphids: their biology, natural enemies and control. World crop pests 2A, Elsevier, Amsterdam, The Netherlands, pp 269-287.

Ebadollah A, Ziaee M, Palla F (2020) Essential Oils Extracted from Deferent Species of the Lamiaceae Plant Family as Prospective Bioagents against Several Detrimental Pests. Molecules 25: 1556.

Erdogan P, Yildirim A (2016) Insecticidal activity of three plant extracts on the green peach aphid [(Myzus persicae Sulzer) (Hemiptera: Aphididae)]. J Entomol Res Soc 18: 27-35.

Henderson CF, Tilton EW (1955) Tests with acaricides against the brow wheat mite. J Econ Entomol 48: 157-161.

Isikber AA, Alma MH, Kanat M, Karci A (2006) Fumigant toxicity of essential oils from Laurus nobilis and Rosmarinus officinalis against all life stage of Tribolium confusum. Phytoparasitica 34: $167-177$.

Jankowska B, Wilk A (2011) Effect of pot marigold (Calendula officinalis L.) and cypress spurge (Euphorbia cyparissias L.) plant water extracts on the occurrence of pest insects on white cabbage. Folia Hort 23: 21-28.

Krzyzowski M, Boran B, Lozowski B, Francikowski J (2020) The effect of Rosmarinus officinalis essential oil fumigation on biochemical, behavioral, and physiological parameters of Callosobruchus maculatus. Insects 11: 344.

Leather SR, Dixon AFG (1984) Aphid growth and reproductive rate. Entomol Expn Appl 35: 137-140.

Lee BH, Lee SE, Annis PC, Pratt SJ, Tumaalii F (2002) Fumigant toxicity of essential oils and monoterpenes against the red flour beetle, Tribolium castaneum Herbst. J Asia Pac Entomol 5: $237-240$.

Mdellel L, Adouani R, Ben Halima KM (2019). Influence of compost fertilization on the biology and morphology of green peach aphid (Myzus persicae) on pepper. Int J Policy Res 7: 48-54.

Mdellel L, Ben Halima MK (2014) Effects of different cultivars of pepper on the biological parameters of the green peach aphid. Eur J Environ Sci 4: 102-105.

Murovhi J, Phophi MM, Mofongoya P (2020) Efficacy of plant materials in controlling aphids on Okra (Abelmoschus esculentus L. Moench) in Limpopo Province of South Africa. Agronomy 10: 1968.

Mwine J, Damme P, Kamoga V, Kudamba C, Nasuuna M, Jumba F (2011) Ethnobotanical study of pesticidal plants used in Southern Uganda and their need for conservation. J Med Plant Res 5: 1155-1163.

Nahusenay DG, Abate GA (2018) Evolution of selected botanical aqueous extracts against cabbage aphid Brevicoryne brassicae L. (Hemiptera: Aphididae) on cabbage (Brassicae oleraceae L.) 
under field condition in Kobo District, North Wollo, Ethiopia. J Hortic For 10: 69-78.

Ofuya TI, Okuku IE (1994) Insecticidal effect of some plant extracts on the cowpea aphid, Aphis craccivora Koch (Homoptera: Aphididae). Anz Schad Pflanz Unweltschutz 67: 127-129.

Ramade F (2003) Éléments d'écologie, Ecologie fondamentale. $3^{\text {rd }}$ edition, Dunod.

Samarasekera R, Weerasinghe IS, Hemalal KDP (2008) Insecticidal activity of menthol derivatives against mosquitoes. Pest Manag Sci 64: 290-295.

Sarwar M (2015) The killer chemicals for control of agriculture insect pests: The botanical insecticides. Int J Cheam Biomol Sci 1: $123-128$.

Satar S, Kersting U, Uygun N (2008) Effect of temperature on population parameters of Aphis gossypii Glover and Myzus persicae Sulzer (Homoptera: Aphididae) on pepper. J Plant Dis Protec 115: 69-74.

Sayed SM, Alotaibi SS, Gaber N, Elarrnaouty SA (2020) Evaluation of five medicinal plant extracts on Aphis craccivora (Hemiptera: Aphididae) and its predator Chrysoperla carnea (Neuroptera: Chrysopidae) under laboratory conditions. Insects 11: 398.
Sertkaya E, Kaya K, Soylu S (2010) Acaricidal activities of the essential oils from several medicinal plants against the carmine spider mite (Tetranychus cinnabarinus Boisd) (Acarina: Tetranychidae). Ind Crops Prod 31: 107-112.

Shawkat MS, Khazaal AQ, Majeed MR (2011) Extraction of pyrethrins from Chrysanthemum cinerariaefolium petals and study its activity against beetle flour Tribolium castanum. Iraq J Scien 52: 456-463.

Silva RPFF, Rocha-Santos TAP, Duarte AC (2016) Supercritical fluid extraction of bioactive compounds. Trends Anal Chem 76: $40-51$.

SPSS (2015) Statistics for windows (version 23.0), IBM CORP.: Armonk, NY, USA; Chicago, IL, USA.

Tripodi P, Kumar S (2019) The Capsicum crop: An introduction. Book chapters. Cham, Switzerland, Springer Intern Pub.

Ukiya M, Akihisa T, Yasukawa K (2006) Anti-inflammatory, anti-tumor-promoting, and cytotoxic activities of constituents of pot marigold (Calendula officinalis) flowers. J Nat Prod 69: 1692-1696.

Van Emden HF, R Harrington (2007) Aphids as crop pests. CABI Publishing, London. 